Dokuz Eylül Üniversitesi-Mühendislik Fakültesi

Fen ve Mühendislik Dergisi

Cilt 20, Sayı 60, Eylül, 2018
Dokuz Eylul University-Faculty of Engineering Journal of Science and Engineering Volume 20, Issue 60, September, 2018

DOI: $10.21205 /$ deufmd. 2018206070

\title{
Akım Gözlemi Olmayan Havzalarda Taşkın Akımlarının Belirlenmesi: Kızıldere Havzası
}

\author{
Ahmet Ali KUMANLIOĞLU*1, Satuk Buğra ERSOY2 \\ ${ }^{1}$ Manisa Celal Bayar Üniversitesi, Mühendislik Fakültesi, İnşaat Mühendisliği Bölümü, 45140, \\ Manisa. (ORCID: 0000-0001-7073-0322) \\ 2İl Afet ve Acil Durum Müdürlügü̈, 35050, İzmir
}

(Alınış / Received: 20.02.2018, Kabul / Accepted: 18.04.2018, Online Yayınlanma / Published Online: 15.09.2018)

Anahtar Kelimeler Özet: Sunulan çalışmada Gediz Nehrinin bir yan kolu olan ve üzerinde herhangi bir akım gözlem istasyonu olmayan Kızıldere

Kızıldere deresi

Mockus

Yöntemi deresinin 2, 5, 10, 25, 50, 100, 500 ve 1000 yıl tekerrürlü taşkın akımları belirlenmiştir. Taşkın akımlarının belirlenmesinde

Taşkın akımı Mockus yöntemi kullanılmıştır. Kızıldere deresi havzasını temsil eden meteoroloji gözlem istasyonları olan Muradiye ve Üçpınar istayonlarında gözlemlenen yağıș verileri kullanılmıştır. Yağış verilerinin istatistiksel analizleri yaplarak verilere en uygun dağılım belirlenmiştir. Yağış verilerine en uygun dağılım istatistik testler vasıtasıyla Log-pearson Tip-3 dağılımı olduğu bulunmuștur. Bu dağılım ile Soil Conservation Service (SCS) ve Mockus yöntemi kullanılarak, 2, 5, 10, 25, 50, 100, 500 tekerrürlü yıllık maksimum yağış yükseklikleri hesaplanmıştır. Hesaplanan yağış verileri ile Kızıldere Deresine ait 2, 5, 10, 25, 50, 100, 500 ve 1000 yıl tekerrülü taşkın akımları havzanın Mockus yönteminden elde edilen birim hidrografi ile bulunmuştur..

\section{Determination of Flood Currents in Basins without Current Monitoring: Kızıldere Basin}

Keywords
Kizıldere
Tributary
Mockuc Method
Floods currents

Abstract: In this study, 2, 5, 10, 25, 50, 100, 500 and 1000 years repetitive flood currents of Kizıldere, which is a sidewall of Gediz River were determined. The Mockus method was used to determine flood currents. Rainfall data observed in Muradiye and Üçpınar stations, which are meteorological observation stations representing Kızılderere basin, were used. Statistical analyzes of precipitation data were performed to determine the most appropriate distribution. The most suitable distribution for rainfall data was found to be Log-Pearson Type-3 distribution through statistical tests. With this distribution, maximum annual precipitation heights of 2, 5, 10, 25, 50, 100, 500 repetitions were calculated by using Soil Conservation Service (SCS) and Mockus method. The flood currents of 2, 5, 10, 25, 50, 100, 500 and 1000 
years belonging to Kizlldere Tributary and calculated hydrographs were found by unit hydrograph obtained from Mockus method of the basin

*Sorumlu yazar: ahmet.kumanlioglu@cbu.edu.tr

\section{Giris}

Taşkınlar, bir akarsuyun farklı sebeplerle yatağından taşarak veya farklı nedenlerle yükselen suların yerleşim yerlerine, alt yapı ve üst yapı tesislerine, verimli tarımsal alanlara ve bölgedeki canlılara zarar vermesi sonucu doğal afet olarak tanımlanır $[1,2,3,4]$. Ülkemizde sık görülen taşkınlar, doğal afetlerin oluşturduğu zararlar, depremden sonra ekonomik kayıplar açısından ikinci sırada yer almaktadır $[5,6,7,8,9]$. Tașkınlar, ana yapısına ek olarak hatalı arazi kullanımı, doğal afet birikintisinin yok edilmesi, dere ve yataklarına usulsüz yerleşimler ve erozyon gibi etkilerle temelde insan müdahalesine bağlı olarak meydana gelen olaylardır [4, 6, 10 11, 12, 13, 14].

Yerleşim ve tarım alanlarının taşkın felaketlerinden korumak ve önlemek amacıyla ülkemizde ve dünyada birçok çalışmalar yapılmaktadır $[15,16,17,18$, 19]. Özellikle drenaj alanı fazla ve taşkın debi değerleri yüksek olan akarsuların kıyısında yapılaşmaya müsait olan düzlük alanlar yerleşim yerleri olarak ve akarsu kıyısındaki verimli araziler tarımsal alan olarak seçilirken, arazinin taşkına maruz olup olmadığı hususu dikkate alınması gereken ilk ve en önemli unsurdur $[20,21$, 22].

Havza yönetimi ve taşkın modellerinin oluşturulmasında akım gözlemi olmayan havzalarda taşkın akımlarının doğru belirlenmesi çok önemlidir. Taşkın modellerinde taşkın alanlarının belirlenmesi, haritalandırıması ve bunların doğrultusunda havza yönetiminin planlanması yapılmaktadır. Taşkın modellerinin temel girdisini taşkın akımları oluşturmaktadır. $\mathrm{Bu}$ tür çalışmalarda taşkın akımları olası muhtemel taşkın değerinden daha büyük hesaplanmış ise gereken önlemlerin boyutları artacak ve maliyette büyük artışlara sebep olacaktır. Eğer olası muhtemel taşkın değerinden daha az hesaplanmışsa taşkın modelleri gerçeği yansitmayacak buda can veya mal kaybı riskini arttıracaktır $[23,24]$.

Taşkın akımlarının belirlenmesinde üzerinde akım gözlemi olmayan havzalarda Mockus, SCS, Synder ve Kirpich gibi sentetik yöntemler literatürde sıklıkla kullanılmaktadır [2, 25,26 , 27]. Sönmez ve ark. sentetik yöntemlerle ile İstanbul derelerinde görülebilecek olası taşkın debilerini belirlemişler ve Synder yöntemine göre bulunan taşkın debilerinin diğer yöntemlerle hesaplananlardan çok daha büyük olduğunu göstermişlerdir [26]. Sönmez ve ark. Mudurnu Çayı için DSi sentetik yöntemini ve Mockus yöntemini kullanarak taşkın akımlarını hesaplamış ve Mockus yönteminin havzaya ait parametreleri daha fazla kullandığından dolayı, bu yöntemin tașkın akımlarının belirlenmesinde daha uygun olduğunu belirtmişlerdir [27].

Çalışmada üzerinde herhangi bir akım gözlem istasyonu bulunmayan Gediz Havzası Kızıldere Deresi'nin taşkın hidrografları belirlenmiştir. Burada Kızıldere deresi havzasını temsil eden Muradiye ve Üçpınar meteoroloji gözlem istasyonlarında gözlemlenen yağıș verilerine ait uygun istatistiksel dağılımlar belirlenmiştir. İstatistiksel dağılımların belirlenmesinde KolmogrovSmirnov ve Olasilık Çizgisi Korelasyon Testi kullanılmıștır. Bu testler sonucunda belirlenen istatistik dağılımla $2,5,10,25$, $50,100,200$ ve 500 yll tekerrürlü alansal ortalama yağış değerleri bulunmuştur. Bu yağış değerleri kullanılarak Mockus 
yöntemi ile 5, 10, 25, 50, 100, 200, 500 ve $160.30 \mathrm{~m}$ talveg kotunda aks yerine 1000 yıllık taşkın debilerinin birim ulaşır. Beydere Mahallesi girişinde hidrografları çıkarılmıştır.

\section{Materyal ve Metot}

\section{1. Çalıșma alanı}

Kızıldere Deresi Manisa İlimizin, Yunusemre İlçesi sınırlarında yer almaktadır. Kızıldere yaklaşık $500 \mathrm{~m}$ kotlarında olan Karıca Tepe eteklerinden doğar; akıșını güneydoğu istikametinde sürdürerek Karakuzu Tepe eteklerinde güneye yönelerek Kızıldere adını alır. Güneye akmaya devam eden Kizlldere
Soğukpinar Deresine sol sahilden mansaplanıp Soğukpınar Deresi doğu ve batı yönünde akışını sürdürür ve Beydeğirmen Dere adını aldıktan sonra Gediz Nehrine karışır.

Kızldderenin uzunluğu 5.42 km, yağıș alanı $12 \mathrm{~km}^{2}$ 'dir. Bölgede akdeniz iklimi hâkim olup, bitki örtüsü ormanlıktır. Kızıldere'nin konumu gösterir ölçeksiz Google earth görüntüsü Şekil 1'de gösterilmektedir.

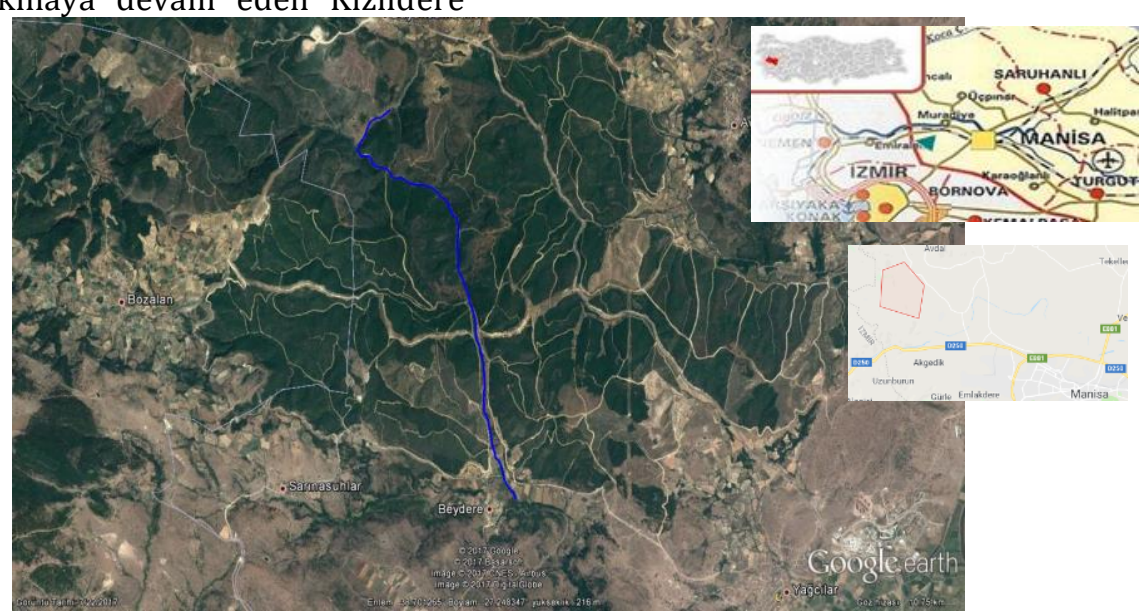

Şekil 1. Kızlldere google earth görüntüsü

Kızıldere havzasının yağış ölçümlerinin hesabında, DSi 2. Bölge Müdürlügünden alınan, MGİ Muradiye, Üçpınar, Beșyol ve Maldan istasyonları yağış ölçüm verileri kullanılmıștır. Thiessen poligonu yöntemine göre, dere yatağını en çok etkileyen istasyonlar \%70 oranında
Muradiye gözlem istasyonu, \%30 oranında da Üçpınar gözlem istasyonudur. MGI Muradiye, Üçpınar, Beşyol ve Maldan istasyonları Thiessen Poligonu ölçeksiz olarak Şekil 2'de verilmiştir. 


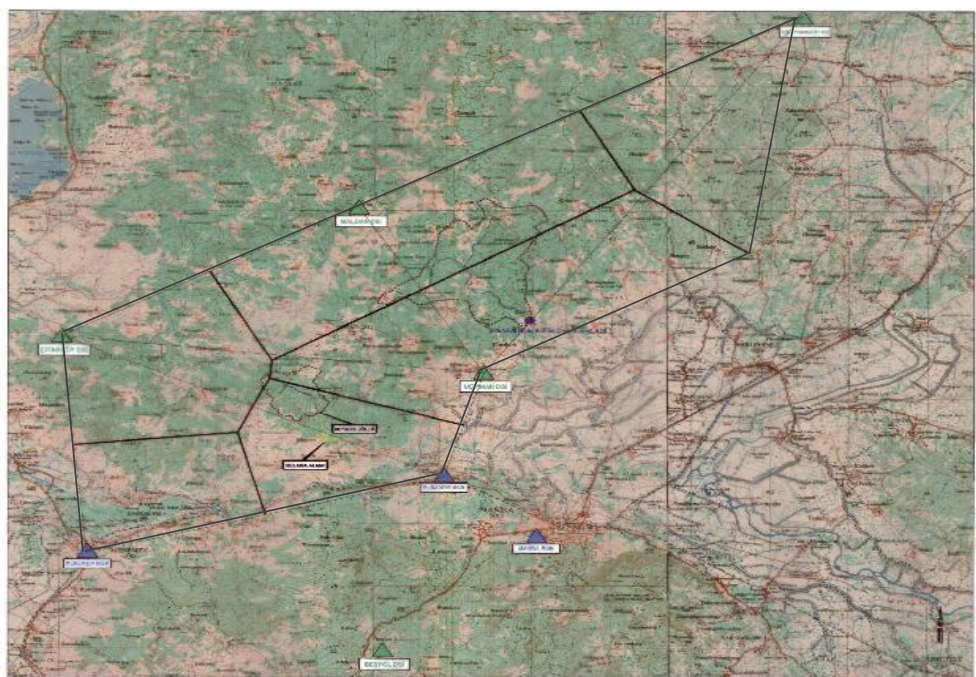

Şekil 2. MGİ Muradiye, Üçpınar, Beşyol ve Maldan istasyonları Thiessen Poligonu

\section{2. İstatistiksel Dağılımlar}

Manisa Kızıldere Deresi taşkın akımlarının belirlenmesinde aşağıda açılanan Normal, Log-Normal, Gumbel, Gama Tip 3 ve Log-Pearson Tip 3 dağılımları kullanılmıştır.

\subsubsection{Normal Dağılım (ND)}

Normal dağılım, iki parametreyle tanımlanır. Bunlar ortalama $(\mu)$ ve standart sapmadır $(\sigma)$. Normal dağılım hesabına ait olasılık yoğunluk fonksiyonu Denklem 1'de ve grafiği Şekil 3'te verilmektedir.

$$
f(x, \mu, \sigma)=\frac{1}{\sigma \sqrt{2 \pi}} e^{-\frac{(x-\mu)^{2}}{2 \sigma^{2}}}
$$

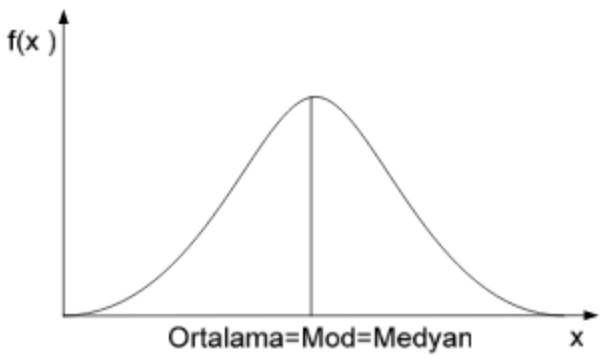

Şekil 3. Normal Dağılım

\subsubsection{Log-Normal Dağılım (LN2)}

Log-Normal olasılık dağılımı, logaritması normal dağılım gösteren herhangi bir rassal değişken için tek kuyruklu bir olasılık dağılımdır.

Bir $x$ rasgele değişkenine ilişkin $\ln x$ olasılık dağılımı normal ise, $x^{\prime}$ in olasılık dağılımı logaritmik normal dağılım ya da kısaca log-normal dağılım terimiyle adlandırılır. Log-Normal dağılım hesabına ait olasılık yoğunluk fonksiyonu Denklem 2'de ve grafiği Șekil 4'te verilmektedir.

$f(x)=\frac{1}{x \sigma_{y} \sqrt{2 \pi}} e^{\frac{-\left(\ln x-\mu_{y}\right)^{2}}{2 \sigma_{y}^{2}}}$

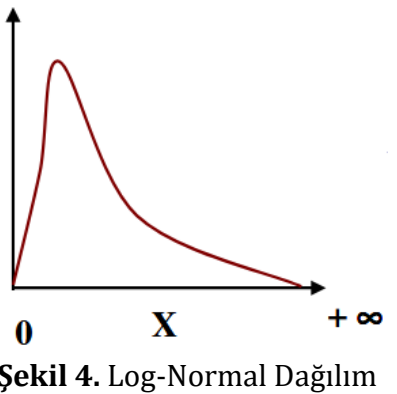




\subsubsection{Gumbel Dağılımı (GD)}

Gumbel dağılımı çeşitli örneklerin bir dizi maksimum veya minimum dağılımını modellemek için kullanılır. Maksimum gözlemlenen değerlerin belirli bir yıl içinde maksimum düzeyde dağılımını göstermek için kullanılır. Bu dağılım deprem, sel veya diğer doğal afetlerin meydana gelme olasılığını tahmin etmede kullanılabilir. Gumbel dağılım hesabına ait olasilık yoğunluk fonksiyonu Denklem 3 'te ve grafiği Şekil 5'te verilmektedir.

$$
F(x)=\exp \left(-e^{-\alpha(x-\beta)}\right)
$$

Formüldeki $\quad \alpha \quad$ ve $\quad \beta \quad$ dağılım parametreleridir.

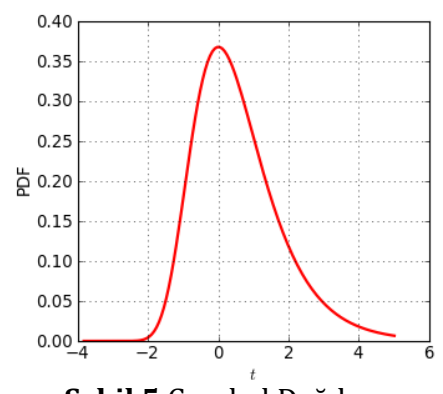

Şekil 5.Gumbel Dağılımı

\subsubsection{Gama Tip 3 Dağılımı (G3)}

Gamma Tip-3 dağılımı iki parametreli sürekli bir olasılık dağılımıdır. Dağılıma ait olasılık dağılım fonksiyonu Denklem 4'te ve grafiği Şekil 6'da verilmektedir.

$$
f(x)=x^{k-1} \frac{e^{-x / \theta}}{\theta^{k} \Gamma(k)} \quad x, \theta, k>0
$$

Formüldeki $\theta$ ölçek parametresine, k şekil parametresine karşıllı gelmektedir. $\Gamma(\mathrm{k})$ (k-1)! olarak alınabilir.

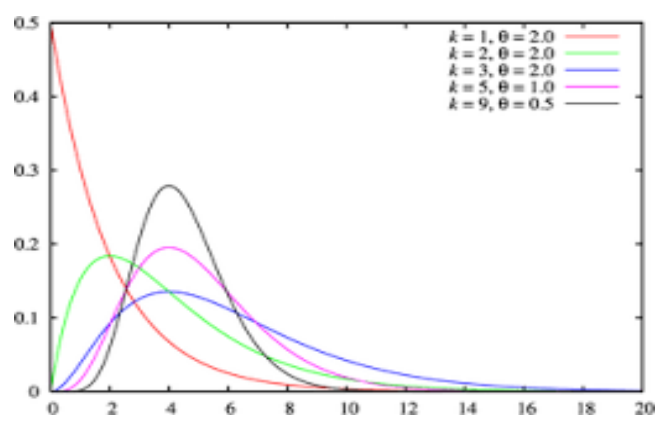

Şekil 6. Gama Tip-3 Dağılımı

2.2.5 Log-Pearson Tip 3 Dağılımı (LP3) Log-Pearson Tip-3 Dağılımına ait olasilık yoğunluk fonksiyonu Denklem 5'te, grafiği Şekil 7'de verilmektedir.

$$
f(x)=|\beta|[\beta(x-\xi)]^{\alpha-1} \frac{e^{(-[\beta(x-\xi)]}}{\tau(\alpha)}
$$

Olasılık yoğunluk fonksiyonu dağılımında $\alpha$ biçim paremetresi, $\beta$ ölçek paremetresi ve $\xi$ yer parametresidir. $\alpha>0, \beta>0$ için $x>\xi$ olup $\xi$ altsınırı oluşturur. $\beta<0$ için ise $x<\xi$ olup $\xi$ üst sınırdır.

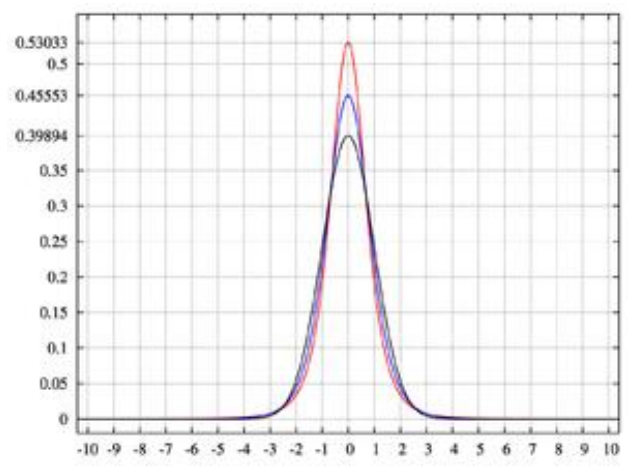

Şekil 7. Log-Pearson Tip-3 Dağılımı

\section{3. İstistiksel Testler}

Eldeki gözlem sonuçlarına en iyi uyan olasılık dağılım fonksiyonu istatistik yöntemler kullanarak belirlenebilir. Dağılımların gözlemlere uygunluğunu kontrol etmek için çalışma kapsamında Kolmogrov-Simirnov testi ve Olasılık Çizgisi Korelasyon testi uygulanmıştır. 
2.3.1. Kolmogorov-Smirnov (K-S) Testi Gözlenen bir verinin, istatistiksel bir metot ile bulunan dağılım sonucunun uygunluğunu kontrol etmek için uygulanır. $\mathrm{Bu}$ test yönteminde gözlenen her bir veri için $\mathrm{F}^{*}\left(x_{i}\right)$ değerleri ve bu veri için kullanılan istatistiksel dağılımın verdiğ $\mathrm{F}\left(x_{i}\right)$ değerleri arasındaki maksimum farkın mutlak değeri bulunur. Bulunan $\Delta$ ile istatistik kitaplarında yer alan veri sayısına ve $\alpha$ anlamlık düzeyine göre belirlenen $\Delta \alpha$ değeri ile karşılaştırılır. $\quad \Delta<\Delta \alpha$ ise belirlenen anlamlık düzeyine göre dağılım K-S testinde kabul edilir. $\mathrm{Bu}$ istatistiksel yöntemin matematiksel ifadesi Denklem 6'da verilmektedir.

$$
\operatorname{Max} \Delta=\left|\mathrm{F}^{*}\left(x_{i}\right)-\mathrm{F}\left(x_{i}\right)\right|
$$

Burada xi gözlem istasyonundan alınan veridir. $\mathrm{F}^{*}\left(x_{i}\right)=\mathrm{i} / \mathrm{N}$ formülüyle hesaplanır. i sıra sayısı, $\mathrm{N}$ toplam veri sayısıdır. $\mathrm{F}\left(x_{i}\right)$ ilgili istatistiksel dağılımın eklenik olasılık dağılım değeridir.

\subsubsection{Olasılık Çizgisi Korelâsyon Testi (OÇKT)}

Gözlenen her bir verinin, $\alpha$ anlamlık değerleri Denklem 7'yardımıyla her bir elemanın aşılmama olasıllığı $\mathrm{F}(x)$ bulunur. Bulunan bu değere karșılık kullanılan istatistiksel metotların ters olasılıkları $\mathrm{F}\left(x_{i}\right)$ hesaplanır.

$$
F(x)=\frac{(i-a)}{N+1-2 a}
$$

$\mathrm{F}(\mathrm{x})$ ve $\mathrm{F}\left(x_{i}\right)$ değerleri arasındaki $\mathrm{r}^{*}$ korelasyon katsayısı hesaplanarak, istatistik kitaplarında yer alan ilgili tablolardan Gumbel Dağılımı, Normal Dağılım, Log-Normal Dağılımı Gama Tip-3 Dağılımı ve Log-Pearson Tip 3 Dağılımının uygun olup olmadığı değerlendirilir.

\subsection{Mockus Yöntemi}

Mockus Yöntemi üzerinde akım gözlem istasyonu bulunmayan havzada geçen debinin belirlenmesinde sıklıkla kullanılan bir yöntemdir. Ayrıca hesabının pratikliği ve üçgen hidrografın çizim kolaylı̆̆ edilmektedir. Toplanma süresi 3 saat veya drenaj alanı daha küçük yerler için uygulanmaktadır.

Taşkın debisini hesaplarken birim hidrograf analizi yapılır. Birim hidrograf analiz grafiği Șekil 8'deki gibidir.

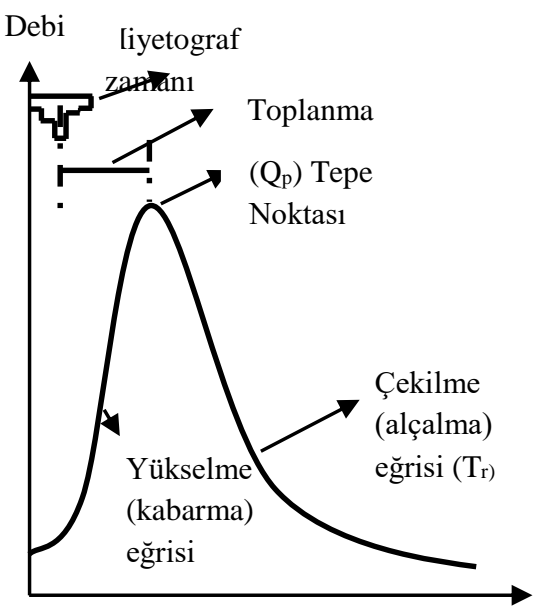

zaman

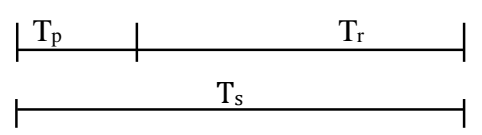

Şekil 8. Hidrograf grafiği

Hidrograf analizinde nehir yatağının harmonik eğimi Denklem 8 ile hesaplanır.

$$
S=\left(\frac{10}{\sum \frac{1}{\sqrt{S_{i}}}}\right)^{2}
$$

Burada S nehir yatağının harmonik eğimini, $S_{i}$ kesitler arası harmonik eğimi göstermektedir.

Harmonik eğime ve nehir yatağı uzunluğuna bağlı olarak havzanın toplanma süresi Denklem 9a'da verilen Kirpich Formülü ile hesaplanır. [28]. 


$$
T_{c}=3.95\left(\frac{L^{2}}{S}\right)^{0.385}
$$

Denklem 9a'da $T_{c}$ havzanın toplanma süresini (dk), L nehir yatağı uzunluğunu $(\mathrm{km})$ ifade etmektedir. $T_{\mathrm{c}}$ toplanma süresi saat (sa) ve L nehir yatağı uzunluğunu (m) cinsinden ifade edildiğinde Denklem $9 b^{\prime}$ ye ulaşılır.

$$
T_{c}=0.00032 \frac{L^{0.77}}{S^{0.385}}
$$

Suların toplanma süresine denk gelen D yağış süresi Denklem 10 yardımı ile bulunur. Uygulamalarda yağış süresi en büyük tamsayıya tamamlanır. Tc'nin 1 saatten küçük çıkması durumunda yağıș süresi değeri toplanma süresine eșit alınır.

$$
D=2 * \sqrt{T_{c}}
$$

Burada D suların toplanma süresine denk gelen yağıș süresini (sa) ifade eder.

Hidrografın yükselme (kabarma) zamanının $\left(\mathrm{T}_{\mathrm{p}}\right)$, suların toplanma süresine denk gelen yağıș süresi ve toplanma süresine bağlı ifadesi Denklem 11 'de verilmektedir.

$$
T_{p}=0.5 D+0.6 T_{c}
$$

Hidrografın çekilme eğrisi $\left(\mathrm{T}_{\mathrm{r}}\right)$, kabarma eğrisinin fonksiyonu olarak Denklem 12 ile bulunmaktadır.

$$
\mathrm{T}_{\mathrm{r}}=1.67 * \mathrm{~T}_{\mathrm{p}}
$$

Taşkın hidrografının taban genişliği $\left(\mathrm{T}_{\mathrm{s}}\right)$, kabarma eğrisi süresi ile çekilme eğrisi süresinin toplamıdır (Denklem 13).

$$
\mathrm{T}_{\mathrm{s}}=\mathrm{T}_{\mathrm{r}}+\mathrm{T}_{\mathrm{p}}
$$

Birim hidrografin birim alana göre pik debisi Denklem 14 yardımıyla bulunur.

$$
\mathrm{q}_{\mathrm{p}}=0.208^{*} \mathrm{~A} / \mathrm{T}_{\mathrm{p}}
$$

Burada $\mathrm{q}_{\mathrm{p}}$ tașkın hidrografının pik debisi $\left(\mathrm{m}^{3} / \mathrm{s} / \mathrm{mm}\right), \quad$ A havza alanı $\left(\mathrm{km}^{2}\right)$ parametresidir.

\subsection{Soil Conservation Service (SCS) Yöntemi}

Havzada verilen bir yağışın oluşturacağı dolaysız akım hidrografının belirlenmesinde hidrolojik uygulamalarda kullanılan Soil Conservation Service (SCS) yöntemi kullanılmıştır. Bu yöntemde artık yağışın hesaplanması Denklem 15'deki gibi yapilır.

$$
P_{e}=(P-0.2 S)^{2} /(P+0.8 S)
$$

Denklem 15'de $P_{e}$ artık yağıșı (mm) göstermektedir. Denklem 15'de yer alan S ise zemin cinsine ve başlangıç nemine bağlı olup CN eğri numaraları ile Denklem 16 'da verildiği gibi hesaplanmaktadır.

$$
\mathrm{S}=((1000 / \mathrm{CN})-10) * 25.4
$$

Maksimum taşkın debisi Denklem 17 yoluyla hesaplanmaktadır.

$$
\mathrm{Q}_{\max }=\left(P_{e} * q_{p}\right)+Q_{b a z}
$$

$P_{e}$ etkin yağışı $(\mathrm{mm}), Q_{p}$ birim hidrograf pik debisi $\left(\mathrm{m}^{3} / \mathrm{s} / \mathrm{mm}\right)$, Qbaz taban akımını $\left(\mathrm{m}^{3} / \mathrm{s}\right)$ ifade etmektedir.

\section{Bulgular}

\subsection{Yağış Verilerinin İstatistiksel Analizi}

Taşkın akımlarının belirlenmesinde Muradiye ve Üçpınar meteoroloji gözlem istasyonlarında (MGİ) gözlemlenen yağış değerleri kullanılmıştır. Herbir MGíde 
gözlemlenen veriler için Normal Dağılım (ND), Log-Normal Dağılım (LN2), Gamma Tip-3 Dağılımı (G3), Gumbel Dağılımı (GD) ve Log-Pearson Tip-3 Dağılımlarına (LP3) ait istatistik parametreleri Tablo 1 'de verilmektedir. ND için Muradiye MGI'de ortalama $65.4 \mathrm{~mm}$ ve standart sapması $20.2 \mathrm{~mm}$, Üçpınar MGI'de ortalama $48 \mathrm{~mm}$ ve standart sapma 21.1 mm'dir. LN2 dağılım için Muradiye MGI'de ortalama $4.1 \mathrm{~mm}$ ve standart sapması ise 0.3 ve Üçpınar MGI'de ortalama $3.8 \mathrm{~mm}$ ve standart sapma 0.4 $\mathrm{mm}$ olarak bulunmuştur. GD parametreleri olan $\alpha$ ve $\beta$ parametreleri
Muradiye MGİ yağış verileri için sırasıyla 0.05 ve 55.4, Üçpınar MGİ yağıș verileri için sırasıyla 0.06 ve 38.4 olarak hesaplanmıştır. G3 dağılımının Muradiye MGİ yağış verileri için biçim parametresi $(\alpha)$ 2, ölçek parametresi $(\beta) 13.6$ ve eşik parametresi $\left(\mathrm{x}_{0}\right) 21$, Üçpınar MGI yağıș verileri için bu parametreler sırasıyla 0.7 , 25.2 ve 29.8 olarak bulunmuştur. LP3 dağılımında ise biçim $(\alpha)$, ölçek $(\beta)$ ve eşik parametreleri Muradiye MGI yağış verileri için sırasıyla $6.8,0.06$ ve 1.4 , Üçpınar MGI yağış verileri için bu parametreler $5.7,0.07$ ve 1.3 olarak hesaplanmıştır.

Tablo 1. Muradiye ve Üçpınar MGİ gözlemlenen yağışların istatistik dağllımlarının parametreleri

\begin{tabular}{cccccccccccccc} 
Dağılım & \multicolumn{1}{c}{$\mathrm{ND}$} & \multicolumn{1}{c}{ LN2 } & \multicolumn{1}{c}{ GD } & \multicolumn{3}{c}{ G3 } & \multicolumn{3}{c}{ LP3 } \\
MGI & $\mu$ & $\sigma$ & $\mu$ & $\sigma$ & $\alpha$ & $\beta$ & $\alpha$ & $\beta$ & x0 & $\alpha$ & $\beta$ & x0 \\
Muradiye & 65.4 & 20.2 & 4.1 & 0.3 & 0.05 & 55.4 & 2.0 & 13.6 & 21.0 & 6.8 & 0.06 & 1.4 \\
Üçpınar & 48.0 & 21.4 & 3.8 & 0.4 & 0.06 & 38.4 & 0.7 & 25.2 & 29.8 & 5.7 & 0.07 & 1.3 \\
\hline
\end{tabular}

Muradiye ve Üçpınar MGİ'deki verilerin istatistik dağılımlarının belirlenmesinde $0.10,0.05$ ve 0.01 anlamlllık düzeyinde uygunluğu Kolmogorov-Smirnov (K-S) ve Olasılık Çizgisi Korelâsyon Testi ile araștırılmıștır. Muradiye ve Üçpınar MGi veriler için uygulanan KolmogorovSmirnov (K-S) test sonuçları Tablo 2'de ve Olasılık Çizgisi Korelâsyon Testi sonuçları Tablo 3'te verilmektedir.

Tablo 2.Muradiye ve Üçpınar MGİ veriler için uygulanan Kolmogorov-Smirnov (K-S) test sonuçları

\begin{tabular}{|c|c|c|c|c|c|c|c|c|}
\hline \multirow{2}{*}{$\begin{array}{l}\text { Dağılım } \\
\text { tipi }\end{array}$} & \multirow[b]{2}{*}{ Mak $\Delta$} & \multicolumn{3}{|c|}{ Muradiye MGI } & \multirow{2}{*}{ Mak $\Delta$} & \multicolumn{3}{|c|}{ Üçpınar MGİ } \\
\hline & & 0.01 & 0.05 & 0.10 & & 0.01 & 0.05 & 0.10 \\
\hline ND & 0.106 & Kabul & Kabul & Kabul & 0.149 & Kabul & Kabul & Kabul \\
\hline LN2 & 0.152 & Kabul & Kabul & Kabul & 0.110 & Kabul & Kabul & Kabul \\
\hline GD & 0.151 & Kabul & Kabul & Kabul & 0.133 & Kabul & Kabul & Kabul \\
\hline G3 & 0.106 & Kabul & Kabul & Kabul & 0.117 & Kabul & Kabul & Kabul \\
\hline LP3 & 0.125 & Kabul & Kabul & Kabul & 0.062 & Kabul & Kabul & Kabul \\
\hline
\end{tabular}

Tablo 3. Muradiye ve Üçpınar MGİ veriler için uygulanan Olasılık Çizgisi Korelâsyon Testi (OÇKT) sonuçları

\begin{tabular}{lcccccccc}
\hline Dağılım & \multicolumn{4}{c}{ Muradiye MGI } & \multicolumn{3}{c}{ Üçpınar MGI } \\
tipi & $\mathrm{r}$ & 0.01 & 0.05 & 0.10 & $\mathrm{r}$ & 0.01 & 0.05 & 0.10 \\
ND & 0.975 & Kabul & Kabul & Kabul & 0.873 & Ret & Ret & Ret \\
LN2 & 0.956 & Kabul & Kabul & Ret & 0.951 & Ret & Ret & Ret \\
GD & 0.946 & Kabul & Kabul & Ret & 0.945 & Kabul & Ret & Ret \\
G3 & 0.932 & Kabul & Ret & Ret & 0.968 & Kabul & Ret & Ret \\
LP3 & 0.958 & Kabul & Kabul & Ret & 0.978 & Kabul & Kabul & Ret \\
\hline
\end{tabular}


Olasılık dağılım fonksiyonlarının K-S testine göre uygunluğunun belirlenmesinde kullanılan $\Delta_{\alpha}$ sinır değerler $0.01,0.05$ ve 0.10 anlamlılık düzeylerinde $(\alpha)$, Muradiye MGİ yağıș verileri için $0.36,0.29,0.26$ ve Üçpınar MGİ yağış verileri için $0.23,0.19$ ve 0.17 'dir. Tablo 2'de verilen dağılımlar için hesaplanan $\Delta_{\text {mak }}$ değerler $\Delta_{\alpha}$ değerlerinden küçük olduğu için olasılık dağllımlarının hepsinin incelenen tüm anlamlılık düzeylerinde uygun olduğunu göstermektedir.

OÇKT'inde $r^{*}$ değeri Gumbel dağılımı haricindeki olasılık dağılımları için 0.01, 0.05 ve 0.10 anlamlılık düzeylerinde Muradiye MGİ verileri için 0.924, 0.949, 0.958, Üçpnıar MGİ verileri için de 0.965 , 0.976 ve 0.980 'dir. Gumbel dağılımı için bu değerler Muradiye MGİ verileri için 0.906, 0.939, 0.952 ve Üçpınat MGI verileri için $0.939,0.964$ ve 0.972 'dir. $r^{*}$ değerleri ile OKÇT sonucunda hesaplanan r değerleri karşılaştırıldığında Muradiye MGI verilerinde ND ve LP3 dağılımın uygunluğu tüm anlamlılık düzeyleri için kabul edilmiştir. LN2 ve GD 0.01 ve 0.05 anlamlılık düzeylerinde kabul edildiği fakat 0.10 anlamlılı düzeyinde ret edilmiștir. G3 dağılımı 0.01 anlamlılık düzeyinde kabul edilmiş fakat diğer düzeylerde ret edilmiştir. Üçpınar MGİ veriler için incelenen olasılık dağılımlarında ND ve LN2 dağılımlarının uygunluğu OKÇT'inde incelenen tüm anlamlılık düzeylerinde ret edilmiştir. GD ve G3 dağılımlarının uygunluğu 0.01 anlamlılık düzeyinde kabul edilmiş fakat diğer düzeylerde ret edilmiștir. LP3 dağllımının uygunluğunda ise 0.01 ve 0.05 anlamlılık düzeylerinde kabul edilmiş ancak 0.10 düzeyinde ret edilmiştir (Tablo 3).

Tablo 2 ve Tablo 3'te yer alan sonuçlar beraber incelendiğinde Muradiye ve Üçpınar MGİ'de gözlemlenen veriler için en uygun olasılık dağılım fonksiyonunun LP3 olduğu görülmektedir. Bunun sonucunda $2,5,10,25,50,100,200$ ve 500 yıl tekerrürlü taşkın akımlarının hesaplanmasında LP3 dağılımından elde edilen maksimum yağış değerleri kullanılmıștır. Kızıldere havzası taşkın akımlarının belirlenmesinde kullanılacak olan alansal ortalama maksimum yağıș Thiessen oranları kullanılarak hesaplanmış ve Tablo 4'te sunulmuştur.

Tablo 4. LP3 dağılımından elde edilen maksimum yağıș ve alansal ortalama maksimum yağış

\begin{tabular}{|c|c|c|c|c|c|c|c|c|}
\hline \multirow{2}{*}{$\begin{array}{l}\text { Yağıș } \\
\text { (mm) }\end{array}$} & \multicolumn{8}{|c|}{ Tekerrür yılları } \\
\hline & 2 & 5 & 10 & 25 & 50 & 100 & 200 & 500 \\
\hline Muradiye & 64.06 & 82.96 & 93.47 & 104.93 & 112.38 & 119.08 & 125.13 & 131.48 \\
\hline Üçpınar & 42.44 & 59.24 & 72.70 & 92.67 & 109.89 & 129.29 & 151.21 & 176.85 \\
\hline $\begin{array}{l}\text { Alansal } \\
\text { ortalama } \\
\text { yağış }\end{array}$ & 57.57 & 75.85 & 87.24 & 101.25 & 111.64 & 122.14 & 132.95 & 145.09 \\
\hline
\end{tabular}




\subsection{Taşkın Akımı Hesabı}

Kızıldere havzası taşkın debisinin belirlenmesinde Mocus Yöntemi kullanılmıştır. Mockus Yöntemi ile taşkın yinelenme debilerinin hesabında havzanın eğri numarası CNıl, havzanın bitki örtüsü ve jeolojik yapısı birlikte irdelenerek 70 olarak tespit edilmiştir.

Kızıl Dere Harmonik eğim hesabı Tablo 5 'te verilmiştir. Havzanın toplanma süresinin hesabında havza eğimi Denklem 8 yardımıyla 0.044 ve toplanma süresi Denklem 9b ile 0.80 saat bulunmuştur. Yağış süresi (D) toplanma süresine bağlı olarak 1.79 saat hesaplanmıştır (Denklem 10). Yağış süresi 2 saat alınarak Denklem 11 ile hidrografın yükselme zamanı 1.48 saat bulunmuştur. Havzanın çekilme eğrisi, yükselme eğrisinin fonksiyonu olarak 2.47 saat hesaplanmıştır (Denklem
12). Tașkın hidrografın taban genișliği Denklem 13 ile 3.95 saat bulunmuștur. Birim hidrografin birim alana göre pik debisi ( $\mathrm{q}_{\mathrm{p}}$ ) Denklem 14 ile $1.69 \mathrm{~m}^{3} / \mathrm{s} / \mathrm{mm}$ olarak hesaplanmıştır (Tablo 6).

Tablo 5. Harmonik eğim hesap tablosu

\begin{tabular}{ccccc}
\hline Sira & $\mathrm{H}$ & $\mathrm{H}$ & $l=L / 10(m)$ & $\sqrt{1 / h}$ \\
No & $(\mathrm{m})$ & $(\mathrm{m})$ & & \\
0 & 163 & 0 & & \\
1 & 170 & 7 & & 8.80 \\
2 & 187 & 17 & & 5.65 \\
3 & 210 & 23 & & 4.85 \\
4 & 248 & 38 & & 3.78 \\
5 & 259 & 11 & 542 & 7.02 \\
6 & 282 & 23 & & 4.85 \\
7 & 330 & 48 & & 3.36 \\
8 & 401 & 71 & & 2.76 \\
9 & 452 & 51 & & 3.26 \\
10 & 497 & 45 & & 3.47 \\
& 334 & 334 & & 47.80 \\
\hline
\end{tabular}

Tablo 6. Birim hidrograf parametreleri

\begin{tabular}{ccccccc}
\hline $\mathrm{S}$ & $\mathrm{T}_{\mathrm{c}}$ (saat) & $\mathrm{D}$ (saat) & $\mathrm{T}_{\mathrm{p}}$ (saat) & $\mathrm{T}_{\mathrm{r}}$ (saat) & $\mathrm{T}_{\mathrm{s}}$ (saat) & $\mathrm{q}_{\mathrm{p}}\left(\mathrm{m}^{3} / \mathrm{s} / \mathrm{mm}\right)$ \\
0.044 & 0.8 & 2 & 1.48 & 2.47 & 3.95 & 1.69 \\
\hline
\end{tabular}

Havzaya düșen yağıșın oluşturacağı yükseklikleri ( $\mathrm{Pe}$ ) hesaplanmıștır (Tablo dolaysız akımın hidrografının 7). Denklem 15'te yer alan $\mathrm{S}$ değeri $\mathrm{CN}_{\mathrm{u}}$ belirlenmesi SCS yöntemiyle yapılmıștır. eğri numarası 70 alınarak Denklem 16 ile Havzada Denklem 15 yardımıyla 2, 5, 10, 108.86 olarak hesaplanmıștır.

25, 50 ve 100 yıl tekerrürlü artık yağıș

Tablo 7. Kızıldere havzası 2, 5, 10, 25, 50 ve 100 yıl tekerrürlü artık yağış yükseklikleri

Artık

yağıș

$(\mathrm{mm})$

$\mathrm{Pe}_{\mathrm{e}}$

)
Tekerrür aralı̆̆ı (yıl)

Kızıldere havzası birim hidrograf değerleri Tablo 8'de, birim hidrograf grafiği Şekil 9'da verilmektedir.

Tablo 8 Kızıldere havzası birim hidrografı

\begin{tabular}{lllllllllll}
\hline $\mathrm{T}$ (saat) & 0.00 & 0.50 & 1.00 & 1.48 & 1.50 & 2.00 & 2.50 & 3.00 & 3.50 & 3.95 \\
$\mathrm{Q}_{\mathrm{p}}$ & 0.00 & 0.57 & 1.14 & 1.69 & 1.68 & 1.33 & 0.99 & 0.65 & 0.31 & 0.00 \\
$\left(\mathrm{~m}^{3} / \mathrm{s} / \mathrm{mm}\right)$ & & & & & & & & \\
\hline
\end{tabular}


A.A. Kumanlığlu vd.. / Akım Gözlemi Olmayan Havzalarda Taşkın Akımlarının Belirlenmesi: Kızıldere Havzası

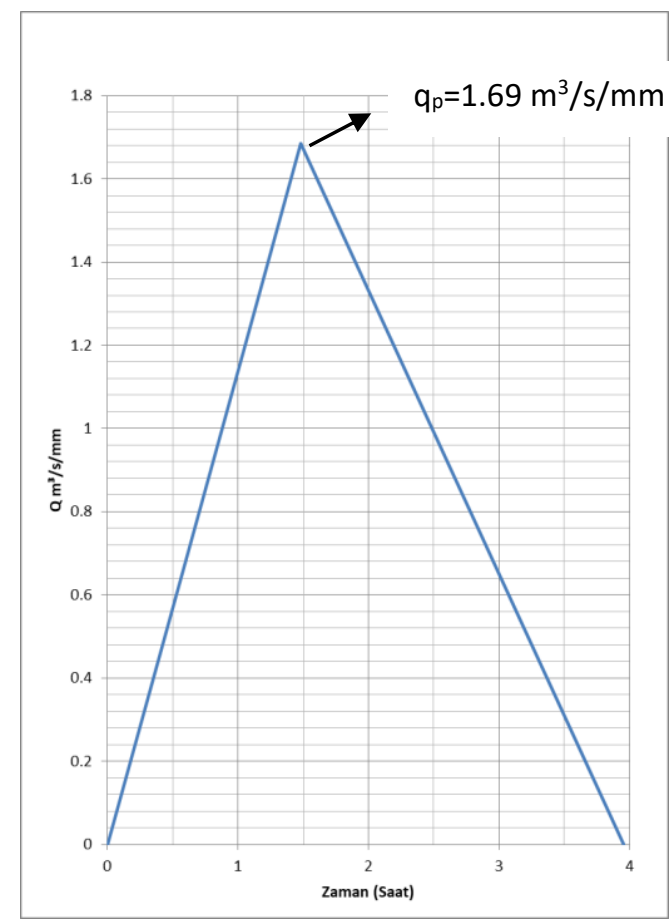

Şekil 9. Kızıldere havzası birim hidrograf grafiği

Taşkın akımlarının belirlenmesinde taban akımı Sarmaçayı havzasında gözlenen akımlar kullanılarak Denklem 18 ile hesaplanmiştır.

$\left(\frac{A_{1}}{A_{2}}\right)^{2 / 3}=\frac{Q_{1}}{Q_{2}}$

Burada, A1 Kızıldere havza alanı $\left(12 \mathrm{~km}^{2}\right)$, $\mathrm{A}_{2}$ Sarmaçayı havza alanı $\left(52.3 \mathrm{~km}^{2}\right), \mathrm{Q}_{2}$
Sarmalçayı akımıdır (1.96 $\left.\mathrm{m}^{3} / \mathrm{s}\right)$. Denklem 18 ile Kızıldere havzası taban akımı $0.73 \mathrm{~m}^{3} / \mathrm{s}$ olarak hesaplanmıştır.

$2,5,10,25,50$ ve 100 yll tekerrürlü maksimum taşkın debileri $\left(\mathrm{Q}_{\max }\right), \mathrm{Q}_{\text {taban }}$ akımı $0.73 \mathrm{~m}^{3} / \mathrm{s}$ alınarak Denklem 17 yardımıyla hesaplanmış ve Tablo 9'da verilmiștir.

Tablo 9. 2, 5, 10, 25, 50 ve 100 yıl tekerrürlü maksimum taşkın debileri

\begin{tabular}{|c|c|c|c|c|c|c|}
\hline \multirow{2}{*}{$\begin{array}{l}\text { Maksimum } \\
\text { Taşkın } \\
\text { Debisi } \\
\left(\mathrm{m}^{3} / \mathrm{s}\right)\end{array}$} & \multicolumn{6}{|c|}{ Tekerrür aralığı (yıl) } \\
\hline & 2 & 5 & 10 & 25 & 50 & 100 \\
\hline $\mathrm{Q}_{\max }$ & 2.73 & 7.33 & 11.26 & 17.00 & 21.82 & 27.12 \\
\hline
\end{tabular}

500 ve 1000 yıllık tașkın debi hesabında

$$
Q_{T}=Q_{10}+Z T * Q_{100}-Q_{10}
$$
Denklem 19 kullanılmıştır. 
A.A. Kumanlığlu vd.. / Akım Gözlemi Olmayan Havzalarda Taşkın Akımlarının Belirlenmesi: Kızıldere Havzası

Formüldeki ZT parametresinin formülü Denklem 20'de verilmiştir.

$$
Z T=0.99 * \log T-0.98
$$

Denklem 19 ile $\mathrm{Q}_{500} 38.10 \mathrm{~m}^{3} / \mathrm{s}$ ve $\mathrm{Q}_{1000}$ $42.83 \mathrm{~m}^{3} / \mathrm{s}$ olarak hesaplanmiștır.

Kızıldere havzası birim hidrograf değerleri Tablo 10'da, birim hidrograf grafiği Şekil 10'da verilmektedir.

Tablo 10. Mocus yöntemine göre 2, 5, 10, 25, 50, 100, 500 ve 1000 yıllık tekerrürlü taşkın debileri

\begin{tabular}{lcccccccc}
\hline Tekerrür (Yll) & 2 & 5 & 10 & 25 & 50 & 100 & 500 & 1000 \\
$\mathrm{Q}\left(\mathrm{m}^{3} / \mathrm{s}\right)$ & 2.73 & 7.33 & 11.26 & 17.00 & 21.82 & 27.12 & 38.10 & 42.83 \\
\hline
\end{tabular}

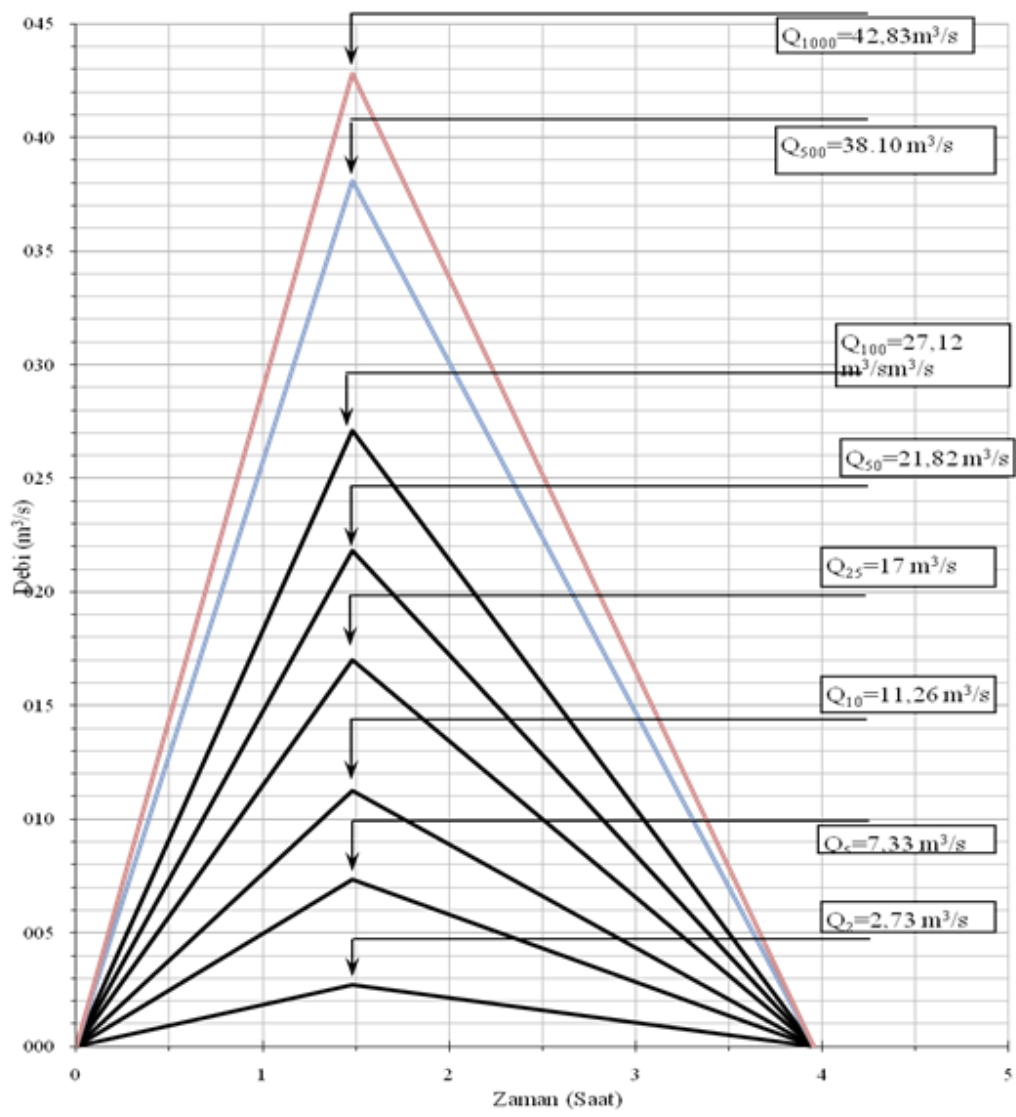

Şekil 10. Kızıldere havzası 2, 5, 10, 25, 50, 100, 500 ve 1000 yıl tekerrürlü taşkın debilerinin birim hidrografları

\section{Tartışma ve Sonuç}

Sunulan çalıșmada da üzerinde herhangi bir akım gözlem istasyonu bulunmayan
Kızıldere Deresinde görülebilecek olan 2, $5,10,25,50,100,200,500$ ve 1000 yl 
tekerrürlü taşkın akımları Kongresi, ODTÜ, Ankara,2007, 163 -

hesaplanmıştır.

Muradiye ve Üçpınar MGİ'den alınan yağış verileri doğrultusunda, Normal Dağılım, Log-normal Dağılım, Gama Tip3 Dağılımı, Log-pearson Tip-3 Dağılımı ve Gumbel Dağllımına göre 2, 5, 10, 25, 50, 100, 500 tekerrür yıllık maksimum yağış yükseklileri hesaplanmıştır. Verilere en uygun olasılık dağılım fonksiyonunu belirlemek için Kolmogrov-Simirnov ve Olasılık Çizgisi Korelasyon Testi uygulanmıștır. Testler sonucunda her iki testte de başarılı olan dağılımlardan, yağış yükseklikleri diğer dağılımlara göre daha yüksek sonuç veren Log-Pearson Tip-3 dağılımı seçilmiștir. $\mathrm{Bu}$ olasılık dağılımı sonucunda elde edilen yağış yükseklikleri taşkın akımı hesabında kullanılmıştır.

Debi hesabında öncelikle derenin birim hidrograf analizi yapılarak maksimum birim hidrograf pik debisi hesaplanmıştır. Olasılık dağılım fonksiyonu sonucu bulunan maksimum yağış yükseklikleri akıșa dönüștürülerek etkin yağış yüksekliği bulunmuştur. Mockus ve SCS yöntemi ile bulunan birim hidrograf kullanılarak 2, 5, 10, 25, 50, 100,500 ve 1000 yll tekerrürlü taşkın akımları bulunmuştur.

Bölgede görülebilecek taşkınlar sebebi ile tarımsal açıdan verimli olan havza su altında kalmaması için gerek ekonomik açıdan gerek ise can ve mal kaybı riskini minimuma indirebilmek açısından bu tür çalışmalar önemli bir yer tutmaktadır.

\section{Kaynakça}

[1] Kömüşçü, A.Ü., Ceylan, A. 1950-2005 Maksimum Ortalama Şiddetli Yağış Verilerinin Türkiye'de Taşkın Risk Alanlarının Belirlenmesine Yönelik Yorumlanması, V. Ulusal Hidroloji 171.

[2] Şen Z., 2009. Taşkın afet ve modern hesaplama yöntemleri. Su Vakfı Yayınları, İstanbul.

[3] Koç C, Kosif K, Kızıltepe S, Eroğlu H, Şirin 0., 2010. Taşkından koruma tesislerine müdahaleler ve ülkemizde yaşanan taşkın olaylarının değerlendirilmesi. II. Ulusal Taşkın Sempozyumu, T.C. Orman Bakanlığı, Afyonkarahisar, 125-140.

[4] Sarıcan, Y, 2013. Taş̧ıı Tehlikesinin Belirlenmesi Amacı İle Otomatik Yağış Miktarı Ölçüm Sisteminin Geliştirilmesi. Hacettepe Üniversitesi, Fen Bilimleri Enstitüsü, Yüksek Lisans, 124 s.

[5] Onuşluel, G.,Harmancioğlu, N.B., 2002. Su Kaynaklı Doğal Afet: Taşkın, Türkiye Mühendislik Haberleri, Sayı 420-421-422/4-5-6.

[6] Uşkay, S., Aksu, S., 2002. Ülkemizde Taşkınlar, Nedenleri, Zararları Ve Alınması Gereken Önlemler. Türkiye Mühendislik Haberleri, Sayı 420-421422/4-5-6, 133 - 136.

[7] Akay 0, Birinci V, Bulu A., 2010. Taşkın alanlarının planlanması ve yönetimi. . II. Ulusal Taşkın Sempozyumu, T.C. Orman Bakanlığı, Afyonkarahisar, 1-9.

[8] Malkoç F, Öztürk D, Malkoç Y, Tuna H, Yıldız M, 2010. Doğu Karadeniz Havzası için Uygulanan taşkın tahmin yöntemlerinin doğruluğunun araștırılması. VI. Ulusal Hidroloji Kongresi, Pamukkale Üniversitesi, Denizli, 127-140.

[9] Pisleaga, M., Badaluta-Minda, C. 2016. TheFloodImpactFromIlisuaCatchmentA rea On The Environment. Procedia Engineering, , 161, $2168-2172$.

[10] Özcan, O., Musaoğlu, N., Şeker, D. Z. 2009. Taşkın Alanlarının CBS ve Uzaktan Algılama Yardımıyla Belirlenmesi ve 
Risk Yönetimi; Sakarya Havzası Örneği. TMMOB Harita ve Kadostro Mühendisleri Odası, 12. Türkiye Harita Bilimsel ve Teknik Kurultayı, 11-15 Mayıs, Ankara.

[11] Gül Onuşluel G ve Aygün O, 2013. Taşkın potansiyeli yönünden Türkiye akarsu havzalarının mekânsal karakterizasyonu. VII. Ulusal Hidroloji Kongresi, Süleyman Demirel Üniversitesi, Isparta, 393-402.

[12] Arkoç, O., Özşahin B, 2015. Kentsel Planlamada Sinırlamalara Yer bilimlerinin Etkisi ve Coğrafi Bilgi Sistemlerinin Kullanımı. 9th International Sinan Symposium, 21-22 Nisan, Edirne, 117 - 123.

[13] Sakieh, Y., 2017. Understanding The Effect Of Spatial Patterns On The Vulnerability Of Urban Areas To Flooding. International Journal of Disaster Risk Reduction, 25, 125 - 136.

[14] Wilusz, D. C.,Zaitchij, B. F., Anderson, M. C., Hain, C. R., Yllmaz, M. T., Mladenova, I. E., 2017. Monthly Flooded Area Classification Using Low Resolution SAR Imagery In The Sudd Wetland From 2007 To 2011. Remote Sensing of Enviroment, 194, 205 - 218.

[15] Tünay, M., Ateşoğlu, A., 2004. Bartın İli Taşkın Sahalarındaki değişimin Uzaktan Algılama Verileriyle İncelenmesi. Süleyman Demirel Üniversitesi Orman Fakültesi Dergisi, $\mathrm{A}(2), 60$ - 72.

[16] Şamandar, A., Genç, Ö.. 2016. Coğrafi Bilgi Sistemleri ile Düzce Büyük Melen Çay Taşkın Haritasının Oluşturulması. İleri Teknoloji Bilimleri Dergisi, 5(2), $183-189$.

[17] Yao, Q.,Xie, J., Guo, L., Zhang, X., Liu, R., 2016. Analysis And Evaluation of Flash FloodDisasters: A Case Of Lingbao Country Of HenanProvince İn China. Procedia Engineering, 154, 835 - 843.
[18] Batica, J.,Gourbesville, P. Resilience 2016. In Flood Risk Management - A New Communication Tool. Procedia Engineering, 154, 811 - 817.

[19] Tanguy, M.,Chokmani, C., Bernnier, M., Poulin , J., Raymond, S., 2017. River Flood Mapping In Urban Areas Combining Radarsat-2 Data and Flood Return Period Data. Remote Sending of Environment,198, 442 - 459.

[20] Dursun Ö F, 2008. Murat Nehrinin Elazığ ili Palu ilçesi civarındaki taşkın seviyesinin belirlenmesi. Doğu Anadolu Bölgesi Araștırmaları, 130-133.

[21] Tanaka, T.,Tachikawa, Y., Inhikawa, Y., Yorozu, K. , 2017. Impact Assessment Of Upstream Flooding On Extreme Flood Frequency Anaysis By İncorporating A Flood İnundation Model For Flood Risk Assessment. Journal of Hydrology, 554, $370-382$.

[22] Ardaya , A. B., Evers, M., Ribbe, L. , 2017. What In fluences Disaster Risk Perception? Intervention Measures, Flood And Landside Risk Perception of ThePopulationLiving İ Flood Risk Areas İn Rio De Janerio State Brazil. International Journal of Disaster Risk Reduction, 25, 227 - 237.

[23] Anl, A. S., 2006. Giresun Aksu havzası maksimum akımlarının frekans analizi. Akdeniz Üniversitesi, Ziraat Fakültesi Dergisi 19(1), 99 - 106.

[24] Özdemir, H., 2008. Havran Çayı'nın (Balikesir) taşkın sıklık analizinde Gumbel ve Log-Pearson Tip III dağılımlarının karşılaştırılması. Coğrafi Bilimler Dergisi, 6(1), 41 - 53.

[25] Aydın, M., Bağatur, T., 2016. Nakayasu sentetik birim hidrograf metodunun Türkiye havzalarında kullanılabilirliğin incelenmesi: Göksu Nehri havzası örneği. Dicle Üniversitesi Mühendislik Fakültesi Mühendislik Dersigi, 7(3), 377 - 386. 
A.A. Kumanlığlu vd.. / Akım Gözlemi Olmayan Havzalarda Taşkın Akımlarının Belirlenmesi: Kızıldere Havzası

[26] Sönmez, O., Öztürk, M., Doğan, E., 2012. İstanbul derelerinin tașkın debilerinin tahmini. SAÜ Fen Bilimleri Dergisi, 16(2), 130 - 135.

[27] Sönmez, O., Hırça, T., Demir, F., 2017. Akım ölçümü olmayan nehirlerde farklı yağış akış modelleri ile tekerrürlü taşkın debisi hesabı: Mudurnu Çayı öreneği. $5^{\text {th }}$ International Symposium on Innovative Technologies in Engineering and Science. 29-30 September, BakuAzerbaijan. 1091 - 1100. 